\title{
Behind the SCREEN: identifying school refusal themes and sub-themes
}

\section{Marie Gallé-Tessonneau \& David Heyne}

To cite this article: Marie Gallé-Tessonneau \& David Heyne (2020) Behind the SCREEN:

identifying school refusal themes and sub-themes, Emotional and Behavioural Difficulties, 25:2, 139-154, DOI: $10.1080 / 13632752.2020 .1733309$

To link to this article: https://doi.org/10.1080/13632752.2020.1733309

曲 Published online: 14 Mar 2020.

Submit your article to this journal $₫$

Lll Article views: 80

Q View related articles $\asymp$

View Crossmark data 


\title{
Behind the SCREEN: identifying school refusal themes and sub-themes
}

\author{
Marie Gallé-Tessonneau ${ }^{a}$ and David Heyne ${ }^{b}$ \\ aDepartment of Psychology, University of Bordeaux, Bordeaux Cedex, France; beiden University Institute of \\ Psychology, Leiden, The Netherlands
}

\begin{abstract}
School refusal is heterogeneous in aetiology and presentation. The heterogeneity in its presentation, the focus of this study, complicates the conceptualisation and assessment of school refusal. The present study documents the development of a descriptive model of school refusal that was used to inform the development of a questionnaire for identifying manifestations of school refusal (the SChool REfusal EvaluatioN - SCREEN). Semi-structured interviews were conducted with 42 participants: adolescents who display school refusal and those who do not, middle school professionals, and care professionals working with adolescents displaying school refusal. Analysis of interview data led to the organisation of school refusal manifestations according to four main themes comprising ten categories. The four themes were: School, Daily and Family Life, Health, and Socialisation Outside Home and Family. These themes correspond to the various contexts in which school refusal may be manifest. Results support the common notion that school refusal manifestations are not limited to absence from the school context, and are likely to occur outside this environment. This study represents the first empirical analysis of the manifestations of school refusal among French youth displaying school refusal.
\end{abstract}

\section{KEYWORDS}

School refusal; absenteeism; content analysis; interview; adolescent; SCREEN; school refusal evaluation

\section{Introduction}

School plays an important role in a youth's personal and interpersonal development, alongside their academic development. It is also a context in which psychosocial distress and developmental deviations may become evident. When a young person exhibits a school attendance problem (SAP), this may signal their distress as well as current and future risk for problems in development. The consequences of absenteeism include poor school performance, increased risk for unemployment, impaired social functioning, and mental health problems in adulthood (Flakierska-Praquin, Lindström, and Gillberg 1997; Kearney 2008; McCune and Hynes 2005; McShane, Walter, and Rey 2004). Family functioning is also affected (Christogiorgos and Giannakopoulos 2014; Kearney and Bensaheb 2006; McAnanly 1986), particularly in adolescence (Heyne and Sauter 2013).

School refusal (SR) is a type of SAP that involves the experience strong negative emotions when a young person is at school or faced with the prospect of going to school (Berg 1997; Egger, Costello, and Angold 2003; Havik, Bru, and Ertesvåg 2015a). Based on Berg and colleagues' work (Berg 1992, 1997; Berg, Nichols, and Pritchard 1969), SR can be defined according to five criteria: (1) reluctance, severe difficulty in attending school, or frequent refusal to go to school; (2) seeking the comfort and security of home, preferring to remain close to parental figures, especially during school hours; (3) 
displaying evidence of emotional distress when the youth is faced with the prospect of having to go to school, which may take the form of unexplained physical symptoms; (4) absence of serious antisocial tendencies, apart from possible aggressiveness when attempts are made by parents to enforce school attendance; and (5) the parents are aware of the problem and have made reasonable efforts to ensure the presence of the child in school.

While some authors use the umbrella term school refusal behaviour to refer to a range of SAPs including SR and truancy (e.g. Kearney and Silverman 1990), numerous authors prefer to maintain the distinction between SR and truancy (Berg 1992, 1997; Berg, Nichols, and Pritchard 1969; Egger, Costello, and Angold 2003; Elliott and Place 2012; Havik, Bru, and Ertesvåg 2015a; Hella and Bernstein 2012; Heyne, Sauter, and Maynard 2015; Heyne 2006; Salemi and Brown 2003). The distinction is supported by a review which indicates that there is less overlap between SR and truancy than is sometimes suggested (Heyne et al. 2019b). The authors of the present paper maintain the distinction between SR and truancy, subscribing to the commonly held notion that SR is characterised by a youth's experience of strong negative emotions when attending school or faced with the prospect of going to school. Truancy, on the other hand, is often characterised by poor motivation for school or a negative attitude towards school, and a tendency to seek more pleasurable activities outside of school during school time (Berg 1997; Berg et al. 1985). SR is also differentiated from school withdrawal which is often characterised by the parents' ambivalence towards their child's school attendance, or resistance towards the child's attendance. In cases of SR, by contrast, the parents are usually aware of the SAP and have made reasonable efforts to ensure that their child attends school (Heyne, Gren Landell et al., 2019b).

Various studies have employed principal component and cluster analysis to identify characteristics of school-refusing youth, usually in comparison with truanting youth. For example, youth classified as school refusers have been found to display a low level of externalising behaviour relative to truants (Berg et al. 1985; Bools et al. 1990; Knollmann et al. 2013) and higher levels of internalising behaviour including separation anxiety, fear of failure, and depression (Atkinson, Quarrington, Cyr, \& Atkinson, 1989; Bools et al. 1990; Knollmann et al. 2013). Studies also support differentiation from truancy based on the notion that youth who display SR remain at home with the knowledge of their parents (Berg et al. 1985; Knollmann et al. 2013) and experience somatic complaints and high levels of morning symptoms such as reluctance and tears (Berg et al. 1985; Bools et al. 1990).

Despite the long history of efforts to conceptualise and classify SR, consensus is still lacking (Heyne, Gren Landell et al., 2019b). Recently, Gallé-Tessonneau, Doron, and Grondin (2017) reported that twelve different sets of criteria for defining SR were evident across thirty studies. The lack of consensus about the most relevant charcateristics of SR might explain the paucity of instruments dedicated to the assessment of SR. Research aimed at the identification of the most relevant manifestations of SR - its signs or symptoms - would support the generation of items for an instrument that could be used to identify SR. Indeed, the first step of scale construction is to 'determine clearly what it is you want to measure' (DeVellis 2011, 73).

Currently, the manifestations of SR that receive most attention in the literature are absenteeism and anxiety. This is probably explained by the fact that these manifestations are more readily identifiable (Ingul, Havik, and Heyne 2019). However, the conceptualisation of SR based exclusively on absenteeism and anxiety is problematic. There are three key reasons why absenteeism is an insufficient manifestation. Firstly, absenteeism is associated with all types of SAPs, including SR, truancy, and school withdrawal. Thus, while the extent of absenteeism might indicate the severity of SR, absenteeism is not specific to SR. Secondly, Berg et al. (1997) SR criteria suggest that a youth who is reluctant to attend school, but attending nevertheless, may be classified as displaying SR. Thirdly, some absences among youth meeting Berg and colleagues' criteria for SR may be justified (authorised), while other absences may be unjustified (unauthorised), and it can be difficult to tease this out (Reid 2013). For example, parents may write a note to school staff to say that their child is absent due to somatic complaints, but the extent to which the somatic complaints are associated with SR or with an organic illness is unclear. 
The conceptualisation of SR based on the presence of anxiety is also problematic. Firstly, even though anxiety disorders have been diagnosed among youth with SR, only half of youth referred for SR experience an anxiety disorder (Heyne, Sauter, and Maynard 2015). The proportion of nonreferred youth with SR who were diagnosed with any disorder was found to be 25 percent, but this included diagnoses of anxiety disorder, depressive disorder, and disruptive behaviour disorders (Egger, Costello, and Angold 2003). Clearly, disorder-level anxiety did not occur among a majority of youth with SR. Secondly, it is apparent that youth with SR may experience types of psychopathology other than anxiety (Egger, Costello, and Angold 2003; Mcshane, Walter, and Rey 2001).

Recently, Gallé-Tessonneau and Gana (2019) reported on the development and validation of the SCREEN, a SChool REfusal EvaluatioN Scale. The SCREEN was developed to permit assessment of the indicators of SR in adolescence, above and beyond indicators that simply reflect absenteeism or anxiety. To develop the instrument, the authors generated an item pool reflecting 4 themes and 10 sub-themes identified through content analysis of interviews with professionals from education and mental health settings, as well as adolscents with and without SR.

The current study provides a detailed account of the process via which Gallé-Tessonneau and Gana (2019) derived the 4 themes and 10 sub-themes upon which the SCREEN was developed. Understanding the origins of the items in this new instrument supports the face validity of the SCREEN. That is, while the manifestations of SR are commonly reported anecdotally in the literature, the current paper describes the empirical approach employed to identify the main manifestations. Furthermore, explication of the process via which SCREEN items were developed will facilitate efforts to replicate the model in different cultural contexts.

\section{Methodology}

The current study employed an integrative approach based on multi-informant perspectives, to derive a comprehensive picture of the phenomenon of SR. That is, semi-structured interviews were conducted to obtain the perspectives of youth (those displaying SR as well as those not displaying SR) and adults (professionals from education and clinical settings). This methodology is usually used as a first step in generating questionnaire items because it provides verbatim information which can be easily understood by the population with whom the instrument will be used (DeVellis 2011). The study focused on SR in adolescence given that SR seems to be more complex and more likely to be referred for treatment in this developmental period (Berg 1997; Gallé-Tessonneau, Doron, and Grondin 2017; Heyne et al. 2014).

\section{Participants}

Participants recruited for the identification of manifestations of SR are described in Gallé-Tessonneau and Gana (2019), and additional information is provided here. There were forty-two participants divided across four groups: (a) 15 middle school students not displaying SR (8 girls and 7 boys) aged 11-16 years $(M=13.7, S D=1.3)$; (b) 6 adolescents displaying SR ( 2 girls and 4 boys) aged $11-15$ years $(M=13.6$, $S D=1.7)$; (c) 17 middle school professionals (e.g., teacher, school director, school nurse; 12 women and 5 men) aged 32-60 years ( $M=45.4, S D=7.8)$; and (d) 4 care professionals working with adolescents displaying SR (i.e., psychiatrists and psychologists, all women) aged 29-42 years $(M=34.5, S D=5.6$ ).

The 15 middle school students who did not display SR or any form of SAP (no absenteeism in the last month) were recruited from five public middle schools. It should be noted that they were from a classroom situation in which there was at least one student with SR in the current or previous year. The 6 adolescents displaying SR were recruited by psychiatrists in two mental health centres. These adolescents needed to fulfil Berg's (1997) criteria for SR and be French-speaking; youth with intellectual disability or psychosis were excluded. The 17 professionals included school staff from the same five schools attended by the 15 students not displaying SR, along with care professionals working in the two mental health centres from which the youth displaying SR were recruited. 
There were two reasons for including youth not displaying SR as well as middle school professionals and care professionals. First, it provided access to broader information about the manifestations of SR. Adoloescents displaying SR may have difficulty observing and reporting on their own behaviour. This is circumvented by recruiting participants who have observed adolescents displaying SR. Second, as underscored by Graneheim and Lundman (2004), one way to improve the credibility of qualitative research is to select participants with various experiences and perspectives. This helps to shed more light on the research question being addressed.

The parents of all adolescents in the study provided written permission for their child's participation. This study received ethics approval from the national independent Committee of the Protection of Persons.

\section{Materials and procedure}

The semi-structured interview schedules that were developed for this study were briefly described in Gallé-Tessonneau and Gana (2019), along with the pre-testing of the interviews so improvements could be made. Additionnal information is presented here.

A psychologist (first author) conducted the interviews at the schools or in the mental health centres between May and October of 2013. The interview schedules consisted of open-ended questions (between 23 and 30 questions, depending on the group being interviewed) related to two main themes: (1) manifestations of SR; and (2) early identification of SR. For each question in the schedules, there was a prompt for the interviewer to encourage participants to clarify or elaborate upon their initial statements, and to provide examples when appropriate (e.g. What do you mean by that? Do you have further examples of this?).

The interview schedules were tailored to each of the four groups of participants, according to level of vocabulary and knowledge of SR. Some questions were consistent across all four interview schedules (e.g. What do you think are the behaviours at school of adolescents displaying SR? According to you, how can we detect these students earlier?). Other questions were specific to one or several groups. For example, adolescents displaying SR were asked: How would you describe a student displaying SR, to someone who knows nothing about SR?; According to you, what were the first manifestations of your SR?; When did you start wondering about what was happening to you ?; What has changed for you since you started having difficulty going to school? Examples of the questions asked of students not disaplying SR are: What do you think are the behaviours in the classroom of adolescents displaying SR?; What have adolescents displaying SR told you about their feelings? Questions only asked of middle school professionals and care professionals included: According to you, what are the first manifestations of SR?; According to you, what are the differences between the behaviours of youth displaying SR and the behaviours of youth truanting from school ?

\section{Data analysis}

Vermatim transcripts of 42 recorded interviews were prepared by the first author (MGT). These transcripts were analysed with the assistance of a computer software program (NVivo 10仓). All 42 transcripts were analysed as one corpus (and not separately for each of the four groups of participants) to derive a comprehensive multi-informant picture of the phenomenon of SR. A twostep thematic content analysis was conducted, namely inductive and then deductive content analysis (Elo and Kyngäs 2008).

Inductive analysis was necessary because of the absence of a validated model of the manifestations of SR. We applied a 'specific to general' approach using open coding (Elo and Kyngäs 2008). Inductive analysis was performed on 70 percent of the interviews, selected randomly, until a model of the manifestations of SR was created. Interviews were analysed according to three coding levels (Graneheim and Lundman 2004). In level 1 coding, data was examined line by line and the key words and important phrases in the text (meaning units level) were noted. Level 2 coding invovled the 
comparison of meaning units and the creation of categories. Categories are simply coded data that seem to cluster together and may result from the condensing of level 1 codes. Similar meaning units were placed in one category with the same title (categories level). Level 3 coding concerns the title given to central themes that emerge by grouping several categories together (theme level). The three coding levels led to the construction of a model composed of various categories grouped into themes. Categories were created by consensus between the first author of this article and a postgraduate psychology student. This model was then reviewed and validated by a team comprising two experienced researchers in content analysis and one psychologist working with adolescents displaying SR. This team determined that the clarity of the model was very good (i.e., no issues were raised with repsect to the model or the name of the categories and themes).

The deductive content analysis was conducted on the remaining 30 percent of the interviews, following the recommendations of Elo and Kyngäs (2008). The model resulting from inductive analysis was used as the categorisation matrix. The data from the interviews were coded according to these predefined categories. This permitted a check on whether the categories constructed during the inductive analysis were all recovered, providing a final model. All of the previously constructed categories were recovered and no modification of the model was necessary.

\section{Fidelity and quality of data analysis}

Content analysis as a research method is a systematic and objective way to describe and quantify a phenomenon (Elo and Kyngäs 2008). It requires adhering to certain rules of credibility, reliability, and generalisation. In this study, the following recommendations of Graneheim and Lundman (2004) were adhered to: a varied selection of participants (different sources, participants with various experiences and perspectives); a precise description of the participants (description of context and culture, age, gender, role); a data collection method with common questions in the interviews; pre-testing the interview schedules; analysis of the interviews in a random order; comparison of the model and the categories, conducted by experts and researchers; a clear description of the analysis process and the context of the interviews; and measurement of inter-judge agreement (internal validity, Cohen's Kappa coefficient). A dual coding, performed on 20 percent of interviews selected randomly from the 42 interviews, revealed good inter-judge reliability ( $\mathrm{k}=.84$ ) according to Landis and Koch's (1977) recommendations.

\section{Results}

Analysis of the interview data led to the manifestations of SR being organised in four main themes which comprised ten categories, as shown in Figure 1. Six of the ten categories comprised twenty-one subcategories. The four themes are School, Daily and Family Life, Health, and Socialisation Outside Home and Family, described below. Among the whole corpus of verbatim responses, the weight of each theme was 80 percent for School, 15 percent for Daily and Family Life, 3 percent for Health, and 2 percent for Socialisation Outside Home and Family. Most of these manifestations of SR are observed in the school setting. Examples of verbatim responses derived from the interviews are presented in Table 1.

\section{School}

This theme refers to SR manifestations observed in relation to middle school. We distinguished four categories: Going to School, In-Class Time, Inter-Class Time, and Absenteeism. Going to School includes the adolescent's thoughts, attitudes, emotions, and somatic complaints on the way from home to school. InClass Time is about the adolescent's thoughts, attitudes, emotions, and somatic complaints while in class, as well as anything related to her/his academic performance. Inter-Class Time includes the adolescent's thoughts, attitudes, emotions, and somatic complaints while at school but not in class (e.g., in the cafeteria or hallway; during recess break) as well as her/his social interactions with peers and adults. Despite some similarities between the sub-categories of In-Class Time and Inter-Class Time, the inductive 


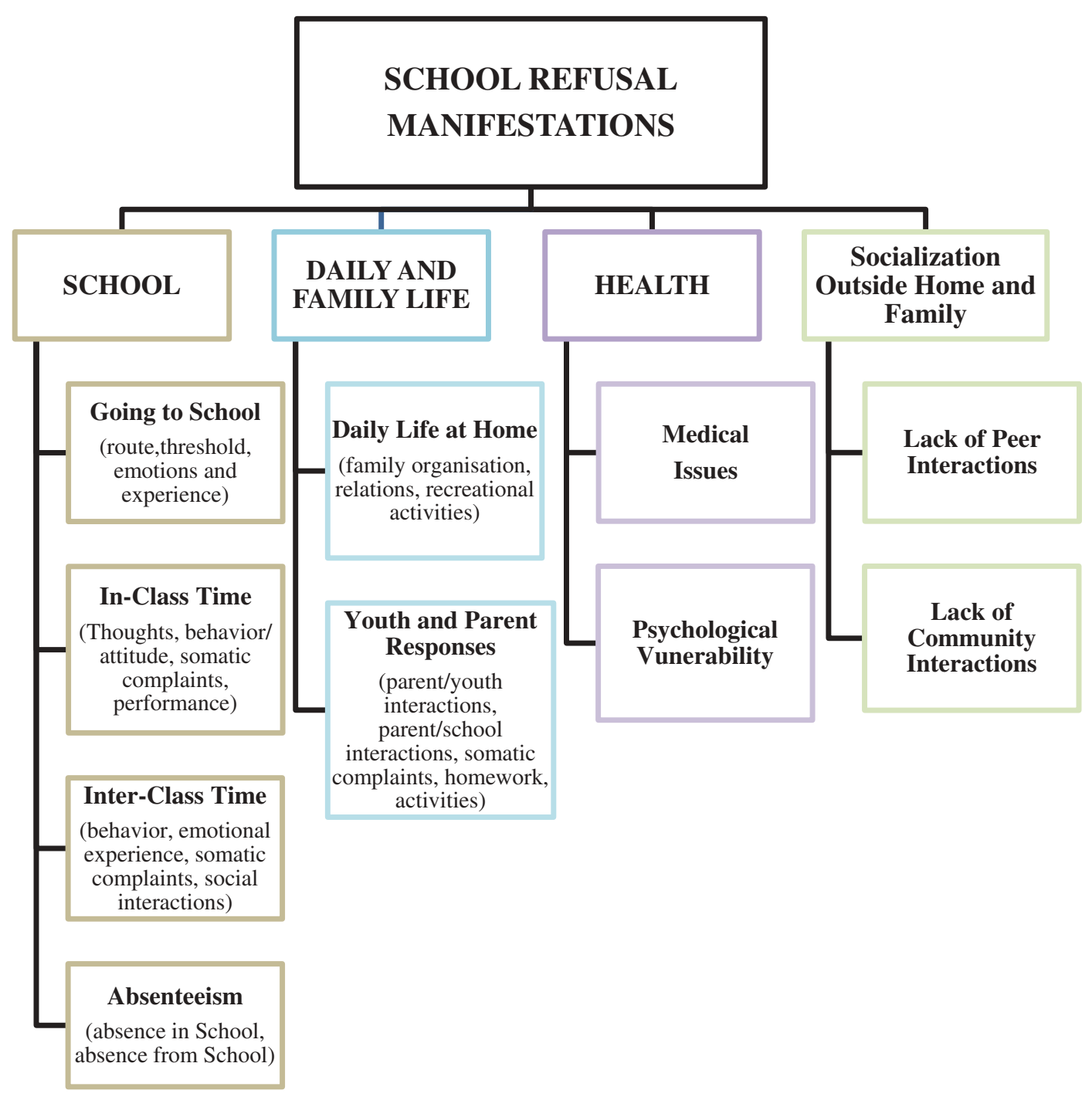

Figure 1. Inventory and organisation of school refusal manifestations: themes, categories, and sub-categories.

process led to the splitting of these two categories based on their differences (i.e., sub-categories performance and social interactions). The Absenteeism category refers to two kinds of absence: absence from school, and absence in school. Absence from school refers to those times when the adolescent is not in school during school hours. Verbatim responses associated with absence from school included patterns of absence, such as absence at particular times of the day, in a week, or across the year (e.g., the morning; Monday; after school holidays). Absence in school refers to the times when the adolescent is physically present on the school premises but not where she/he should ordinarily be (e.g., wandering around the school grounds; in the health centre).

\section{Daily and family life}

This theme refers to SR manifestations observed at home. The two categories here are: Daily Life at Home and Youth and Parent Responses. The Daily Life at Home category refers to the family's everyday activities. It includes the family's routines, relationships with each other, and recreational activities at 
Table 1. Examples of extracts associated with the three levels of thematic analysis encoding.

\begin{tabular}{|c|c|c|c|}
\hline Extracts & Sub-Categories & Categories & Themes \\
\hline "I could not go any more, I was scared of everything» & Feelings & Going to School & School \\
\hline $\begin{array}{l}\text { "From feeling resistant at the time to leave, to feeling } \\
\text { like vomiting in the car» }\end{array}$ & Route to school & & \\
\hline $\begin{array}{l}\text { "The anxiety often comes up at the major back-to- } \\
\text { school times» }\end{array}$ & Threshold & & \\
\hline "All she wants is to leave the classroom» & Feelings & In-Class Time & \\
\hline «Not wanting to answer or speaking at all» & Behaviour & & \\
\hline «In class, I had a stomach ache» & Somatic & & \\
\hline $\begin{array}{l}\text { "A dramatic drop in the results for a child who had so } \\
\text { far performed very well academically» }\end{array}$ & Academic performance & & \\
\hline $\begin{array}{l}\text { «'m not feeling well; I'm not going to make it, staying } \\
\text { out there in recess with my buddies/with the guys?» }\end{array}$ & Feelings, thoughts & Inter-Class Time & \\
\hline $\begin{array}{l}\text { "Children who have become very withdrawn, staying } \\
\text { isolated» }\end{array}$ & Behaviour & & \\
\hline «l felt sick during recess» & Somatic & & \\
\hline $\begin{array}{l}\text { "They're going to be isolated, having no contact with } \\
\text { their classmates» }\end{array}$ & Social interactions & & \\
\hline $\begin{array}{l}\text { "Seeking to avoid the classroom situation, they are } \\
\text { often at the Health Centre» }\end{array}$ & Absence in School & Absenteeism & \\
\hline $\begin{array}{l}\text { "Selective absences ... specifically on Monday } \\
\text { mornings and after breaks» }\end{array}$ & Absence from School & & \\
\hline "l used to have lunch at home» & Organisation & Daily Life at Home & Daily and Family Life \\
\hline $\begin{array}{l}\text { "The parents invest themselves, they are very close to } \\
\text { their child» }\end{array}$ & Family relations & & \\
\hline «On weekends, I see my family, or I just stay home» & Recreational activities & & \\
\hline $\begin{array}{l}\text { "l would catch up on school work, and then I had } \\
\text { private teachers at home» }\end{array}$ & $\begin{array}{l}\text { Activities during } \\
\text { absenteeism }\end{array}$ & $\begin{array}{l}\text { Youth And Parent } \\
\text { Responses }\end{array}$ & \\
\hline «They don't refuse to do their homework» & School Work & & \\
\hline $\begin{array}{l}\text { "My mother would take me to the doctor; I had } \\
\text { a stomach ache. She decided to keep me at home» }\end{array}$ & $\begin{array}{l}\text { Parents/children } \\
\text { interactions }\end{array}$ & & \\
\hline "They are worried; they contact us» & $\begin{array}{l}\text { Parents/School } \\
\text { interactions }\end{array}$ & & \\
\hline «On Sunday night, I have a stomach ache» & Somatic & & \\
\hline «We've had a number of children with obesity issues» & & Medical Issues & Health \\
\hline «I think they were vulnerable» & & $\begin{array}{l}\text { Psychological } \\
\text { Vulnerabilities }\end{array}$ & \\
\hline "I don't see any friends on weekends» & & $\begin{array}{l}\text { Lack of Peer } \\
\text { Interactions }\end{array}$ & \\
\hline «He never goes on summer camp» & & $\begin{array}{l}\text { Lack of Community } \\
\text { Interactions }\end{array}$ & $\begin{array}{l}\text { Socialisation Outside } \\
\text { Home And Family }\end{array}$ \\
\hline
\end{tabular}

home or elsewhere. The Youth and Parent Responses category includes SR manifestations as they appear at home. It takes the following into account: what the child does while missing school, and the management of homework; the somatic complaints as they appear at home (how the adolescent feels); and the interactions between the school, parents, and adolescent.

\section{Health}

The Health theme covers medico-psychological issues relevant to the adolescent. There are two categories: Medical Issues and Psychological Vulnerability. Medical Issues include the adolescent's chronic health issues (e.g., obesity, sleep disorder, epilepsy, asthma). Psychological Vulnerability refers to the adolescent's psychological functioning, including vulnerabilities and disorders (e.g., latent instability, history of psychiatric consultation, separation difficulties in kindergarten).

\section{Socialisation outside home and family}

This theme refers to the adolescent's activities outside of the school and home environments. It includes two categories: Lack of Peer Interactions and Lack of Community Interactions. Lack of Peer 
Interactions refers to the lack of connection with same-age adolescents, including non-participation in typical activities (e.g., not going to birthday parties or the cinema; not having a group of friends). The Lack of Community Interactions category describes the partial or complete lack of participation in community-based activities such as sports clubs and summer camp.

\section{Discussion}

The identification of manifestations of SR is fundamental to developing an instrument to screen for SR. The current study documents the process via which the manifestations of SR were identified for the development of the SCREEN (Gallé-Tessonneau and Gana 2019). Four themes emerged, each comprising a number of categories of manifestations of SR. The four themes correspond to specific contexts in which the manifestations of SR can appear, providing an ecological analysis of SR. We discuss each of the themes and their constitutent categories.

The theme School, and its categories Going to School, In-Class Time, Inter-Class Time, and Absenteeism, provide a picture of the experience that adolescents displaying SR have in different phases of going to and being at school. The category Going to School indicates how difficult the transition between home and school can be for adolescents displaying SR, despite the suggestion that this is more typical of SR in childhood (Nishida et al. 2004). The separation process that occurs when leaving home to go to school encompasses physical and symbolic passages: the route to school, going through the gate, entering the school building, and returning to school in the fall. These passages may revive the anxieties associated with early separations from caregivers such as entering kindergarten (Marcelli and Braconnier 2013).

The category In-Class Time focuses upon academic learning. Interviewees reported that fair, or even good academic performance declined after the onset of SR. In Mcshane et al. (2001) study, 31 percent of adolescents displaying SR had academic difficulties that were associated with the onset of their SR. Another aspect of In-Class Time is the adolescent's disinclincation towards classroom participation (e.g., not raising one's hand; not asking questions). This is consistent with the link found between SR and performance anxiety (Egger, Costello, and Angold 2003).

The category Inter-Class Time points to the difficulty that SR adolescents have in dealing with less formal or structured aspects of school, a point which emerged in Havik, Bru, and Ertesvåg's (2014) study of school factors associated with SR. Conversely, the importance of structure and predictability is underscored by the emphasis given to these facets of school life within interventions aimed at helping adolescents who display chronic and severe SR to re-engage with education (Brouwer-Borghuis et al. 2019). The less structured aspects of school are likely to be the situations where a lack of social skills among some adolescents displaying SR is evidenced. To the extent that adolescents displaying SR experience anxiety in interaction with peers, they are likely to have difficulty negotiating unstructured times that require social skills. Numerous verbatim responses indicated this phenomenon (e.g., I don't feel comfortable with others). The link between SR and social anxiety has been documented by various authors (Blöte et al. 2015; Egger, Costello, and Angold 2003; Mcshane, Walter, and Rey 2001).

The category Absenteeism does not deal with the quantitative aspects of absenteeism, nor does it characterise absence as either justified or unjustified. This is advantageous in view of the problems associated with understanding SR according to these characteristics (see Introduction). Rather, the Absenteeism category points to the form of the absence (i.e., in or from school). Absences in school can be the first indicator of SR (Le Heuzey and Mouren 2010). It should be considered as a sign of distress and alert school staff and clinicians to the emergence or existence of SR. Absences from school often occurred on Mondays and after breaks or vacations. These were short absences that occurred on a regular basis. As such, it is not the overall amount of absence that is the hallmark of SR, a point made by Heyne, King, and Ollendick (2004): 'Absenteeism may be extensive (e.g. consistent absence for months or years at a time), sporadic (e.g. on days involving specific subjects), or nonexistent (e.g. daily distress in going to school during periods of regular attendance)' (323). 
The theme Daily and Family Life includes the category Daily Life at Home. This category refers to daily routines in the life of the family, including household activities (e.g. morning routine; meal-time) and recreational activities (e.g. playing in the yard; watching movies). The adolescents in the current study explained that they would rather spend their free time with their family than go out with friends. In this respect, the emergence of the category Daily Life at Home parallels some of the findings from studies on dynamics in the families of SR youth. In such studies, the intense bond between the adolescent and parents was held to make separation difficult (e.g. Carless et al. 2015; Place et al. 2002).

Another category in the theme Daily and Family Life is Youth And Parent Responses, which indicates that the parents of youth displaying SR communicate regularly with the school (e.g., requests for help; notes explaining absences) and are involved in addressing the consequences of SR (e.g., arranging visits to the doctor; planning for private lessons; discussions with their child). This is consistent with the SR criteria which states that the parents, aware of the problem, have made reasonable efforts to ensure their child goes to school (Heyne, Gren Landell et al., 2019b). In addition, the findings related to this category are consistent with the distinction between SR and school withdrawal, whereby the latter is characterised by parental effort to keep the child at home, or no parental effort to get the child to school (e.g., parents need help at home or refuse to be separated from their child; Heyne, Gren Landell et al., 2019b).

The Health theme comprises two categories, Medical Issues and Psychological Vulnerabilities. It is unsurprising that Health emerged as a theme, given the frequency with which SR has been associated with somatic complaints (Egger, Costello, and Angold 2003; Fujita et al. 2009; Havik, Bru, and Ertesvåg 2015b; Hochadel et al. 2014). In addition, studies have made links between SR and psychological vulnerabilities such as trait anxiety (Richards and Hadwin 2011), psychiatric severity, behavioural problems, and negative personality traits (Ingul and Nordahl 2013).

At this point it is worth noting that somatic manifestations appear in three of the ten categories, as well as the Medical Issues category within the Health theme. Rather than grouping somatic complaints together within one category, it was decided to tease out the specific places and times when these complaints occur (e.g., at home; in class; inter-class). This provides a finer description of the SR phenomenon, which may be important in the early identification of SR (see Implications).

The theme Socialisation Outside Home and Family suggests that adolescents displaying SR struggle in their relationships with peers (category Lack of Peer Interactions) and are quite insular (category Lack of Community Interactions). This is consistent with prior studies indicating that adolescents displaying SR display lower levels of social competence and activity relative to adolescents who do not display SR (Mcshane, Walter, and Rey 2001; Park et al. 2015). Youth displaying SR have also been reported to have more difficulty in their relationships with peers, seldom socialising outside of the home (Egger, Costello, and Angold 2003; Place et al. 2002).

In all, the four themes and their 10 categories represent a broad descriptive model of the manifestations of SR. The empirically-derived themes and categories resonate with the existing literature and appear to be a sound basis for the development of the SCREEN (Gallé-Tessonneau and Gana 2019). No theme or category emerged which focused on the manifestations of anxiety nor the presence of an anxiety disorder. This corresponds with earlier findings that SR is not always associated with anxiety (Egger, Costello, and Angold 2003; Last and Strauss 1990; Mcshane, Walter, and Rey 2001). The four themes - School, Daily and Family Life, Health, and Socialisation Outside Home and Family - indicate that SR is not simply a manifestation of absence from school. While clearly related to school absenteeism, $\mathrm{SR}$ is a more complex phenomenon. For example, the literature points to a relationship between adolescent SR and difficulties negotiating developmental tasks (e.g., Heyne et al. 2014; Rubenstein and Hastings 1980). Indeed, the current study suggests that adolescents displaying SR may have difficulties being away from parents, coping with transitions, and making social connections outside of the family.

\section{Strengths and limitations}

The fact that four themes and ten categories emerged suggests the importance of the interview process to conceptualise the heterogeneous problem of SR. Without the use of semi-structured 
interviews, conducted across four different participant groups, the range of resulting manifestations may have been considerably narrower. At the same time, we acknowledge several limitations of the current study.

First, the sample is limited to 42 participants, so the generalisability of the results to the larger population of youth displaying SR is questionable. Related to this, the number of participants who were youth displaying SR $(n=6)$ and care professionals working with youth displaying $\operatorname{SR}(n=4)$ was relatively small. One reason for this is that we limited recruitment to those care professionals who had a long practice history and considerable experience with SR, to obtain richer information on SR manifestations. Despite the limited number of participants, it it worth noting that the data from interviews with these professionals and from youth displaying SR were homogeneous. In other words, the information from latter interviews did not generate any new themes. This might suggest that recruitment of a larger sample would not have yielded a more generalisable range of themes and categories. At the same time, if a larger sample of care professionals was interviewed, it might have been possible to determine whether there are marked and consistent differences in how care professionals and education professionals describe SR. It is possible that different parties observe different aspects of SR, with settingspecific implications for the assessment of SR in clinical versus school contexts.

A second limitation is that the parents of youth displaying SR were not interviewed. Parent interviews would likely provide additional or more nuanced information about the manifestations of SR.

Third, the study focused exclusively on SR among adolescents. It is possible that the themes found in this study would diverge from the themes that might be found if children displaying SR were interviewed.

\section{Implications for research and practice}

From a research perspective, the details of the method provided in this study (and not included in Gallé-Tessonneau and Gana 2019) can support other researchers who plan to conduct qualitative research via interviews with youth and professionals.

From a practical perspective, the breath of manifestations that emerged in this study - four themes and ten categories - supports the notion that education and mental health professionals need to consider a broad range of variables when conducting assessment and developing an intervention plan for SR. It is not sufficient nor helpful to simply conceptualise the difficulties experienced by a young person displaying SR in terms of diagnoses. For example, the model includes the categories Going to School and Inter-Class Time which may signal critical periods to be included in an exposure hierarchy if conducting cognitive behavioural therapy for SR (e.g. the journey to school or lunch time at school). The model can also foster professionals' attention to areas of relative competence (e.g. no difficulties in peer interactions, but difficulties with transitions between home and school). For example, an adolescent with no difficulties in peer interaction but difficulties with transitions between home and school may be encouraged to go to school with the assistance of peers. Finally, the distinction between absence from school and absence in school highlights one of the first manifestations of SR and thus promotes early detection. Early identification of SR is essential, because a positive prognosis depends on early clinical care (Elliott 1999; Fremont 2003; McAnanly 1986; Okuyama, Okada, Kuribayashi, and Kaneko 1999). Absence from school should be considered a sign of distress and alert school staff and clinicians to the possible emergence or existence of SR. Early detection of SR in the school context (i.e., while the youth is still in school) facilitates the rapid implementation of school-based interventions (Ingul, Havik, and Heyne 2019).

\section{Conclusion}

This study represents the first empirical analysis of the manifestations of SR among French youth displaying SR. Interviews with professionals and youth illuminated a range of SR manifestations in the life of the family, on the way to school, and in the school setting. The study provides a detailed account of the origins of the items in the SCREEN (Gallé-Tessonneau et al. 2018; Gallé-Tessonneau and Gana 
2019), underscoring the empirical support for the model upon which the items were based. It will be important to assess the model's broader applicability by replicating this study in other countries, and including interviews with parents alongside interviews with youth and professionals. These three parties are primary stakeholders to be consulted when conducting research and developing resources for the field of school attendance and absenteeism (Heyne, Gentle Genitty et al., 2019b).

\section{Disclosure statement}

No potential conflict of interest was reported by the authors.

\section{Funding}

The author(s) received no financial support for the research, authorship, and/or publication of this article.

\section{Notes on contributors}

Marie Gallé-Tessonneau is doctor in Psychology, lecturer at the University of Bordeaux, and she works as a psychotherapist in a private practise.

David Heyne is associate professor in the unit Developmental and Educational Psychology of the Institute of Psychology at Leiden University.

\section{Ethical approval}

All procedures performed in studies involving human participants were in accordance with the ethical standards of the institutional and/or national research committee and with the 1964 Helsinki declaration and its later amendments or comparable ethical standards.

\section{Informed consent}

Informed consent was obtained from all individual participants included in the study.

\section{References}

Atkinson, L., B. Quarrington, J. J. Cyr, and F. V Atkinson. (1989). Differential classification in school refusal. British Journal of Psychiatry, 155, 191-195. doi:10.1192/bjp.155.2.191

Berg, I. 1992. "Absence from School and Mental Health." The British Journal of Psychiatry: the Journal of Mental Science 161: 154-166. doi:10.1192/bjp.161.2.154.

Berg, I. 1997. "School Refusal and Truancy." Archives of Disease in Childhood 76 (2): 90-91. doi:10.1136/adc.76.2.90.

Berg, I. 1997. "School Refusal and Truancy." Archives of Disease in Childhood 76 (2): 90-91.

Berg, I., G. Casswell, A. Goodwin, R. Hullin, R. McGuire, and G. Tagg. 1985. "Classification of Severe School Attendance Problems." Psychological Medicine 15 (1): 157-165. doi:10.1017/S0033291700021024.

Berg, I., K. Nichols, and C. Pritchard. 1969. "School Phobia-Its Classification and Relationship to Dependency." Journal of Child Psychology and Psychiatry 10 (2): 123-141. doi:10.1111/j.1469-7610.1969.tb02074.x.

Blöte, A. W., A. C. Miers, D. A. Heyne, and P. M. Westenberg. 2015. "Social Anxiety and the School Environment of Adolescents." In Social Anxiety and Phobia in Adolescents, 151-181. Cham: Springer. doi:10.1007/978-3-319-16703-9_7.

Bools, C., J. Foster, I. Brown, and I. Berg. 1990. "The Identification of Psychiatric Disorders in Children Who Fail to Attend School: A Cluster Analysis of a Non-clinical Population." Psychological Medicine 20 (1): 171-181. doi:10.1017/ S0033291700013350.

Brouwer-Borghuis, M., D. Heyne, F. Sauter, and R. Scholte. 2019. "The Link: An Alternative Educational Program in the Netherlands to Re-engage School-refusing Adolescents with Schooling." Cognitive and Behavioral Practice 26: 75-91. doi:10.1016/j.cbpra.2018.08.001.

Carless, B., G. A. Melvin, B. J. Tonge, and L. K. Newman. 2015. "The Role of Parental Self-efficacy in Adolescent School-refusal." Journal of Family Psychology 29 (2): 162-170. doi:10.1037/fam0000050. 
Christogiorgos, S., and G. Giannakopoulos. 2014. "School Refusal and the Parent-child Relationship: A Psychodynamic Perspective." Journal of Infant, Child, and Adolescent Psychotherapy 13: 182-192. doi:10.1080/15289168.2014.937976. DeVellis, R. F. 2011. Scale Development: Theory and Applications. SAGE.

Egger, H. L., J. E. Costello, and A. Angold. 2003. "School Refusal and Psychiatric Disorders: A Community Study." Journal of the American Academy of Child \& Adolescent Psychiatry 42 (7): 797-807. doi:10.1097/01.CHI.0000046865.56865.79.

Elliott, J., and M. Place. 2012. Children in Difficulty: A Guide to Understanding and Helping. 3rd ed. New York, NY: Routledge/Taylor \& Francis Group.

Elliott, J. G. 1999. "School Refusal: Issues of Conceptualisation, Assessment, and Treatment." Journal of Child Psychology and Psychiatry 40 (7): 1001-1012. doi:10.1111/1469-7610.00519.

Elo, S., and H. Kyngäs. 2008. "The Qualitative Content Analysis Process." Journal of Advanced Nursing 62 (1): $107-115$. doi:10.1111/j.1365-2648.2007.04569.x.

Flakierska-Praquin, N., M. Lindström, and C. Gillberg. 1997. "School Phobia with Separation Anxiety Disorder: A Comparative 20- to 29-year Follow-up Study of 35 School Refusers." Comprehensive Psychiatry 38 (1): 17-22. doi:10.1016/S0010-440X(97)90048-1.

Fremont, W. P. 2003. "School Refusal in Children and Adolescents." American Family Physician 68 (8): 1555-1560.

Fujita, M., J. Fujiwara, T. Maki, K. Shibasaki, M. Shigeta, and J. Nii. 2009. "Pediatric Chronic Daily Headache Associated with School Phobia." Pediatrics International: Official Journal of the Japan Pediatric Society 51 (5): $621-625$. doi:10.1111/j.1442-200X.2009.02804.x.

Gallé-Tessonneau, M., J. Doron, and O. Grondin. 2017. “Des critères de repérage aux stratégies de prise en charge du refus scolaire: Une revue de littérature internationale systématique." Pratiques Psychologiques 23 (1): 1-19. doi:10.1016/j.prps.2016.03.001.

Gallé-Tessonneau, M., and K. Gana. 2019. "Development and Validation of the School Refusal Evaluation Scale for Adolescents." Journal of Pediatric Psychology 44 (2): 153-163. doi:10.1093/jpepsy/jsy061.

Gallé-Tessonneau, M., O. Grondin, M. Koleck, and J. Doron. 2018. "Considérations Méthodologiques Pour La Construction De Questionnaires: L'exemplede La SChool REfusal EvaluatioN (SCREEN). Methodological Considerations for Scale Design. The Example of the SChool REfusal EvaluatioN (SCREEN) Survey." Annales MédicoPsychologiques 176 (9): 863-869. doi:10.1016/j.amp.2017.03.029.

Graneheim, U. H., and B. Lundman. 2004. "Qualitative Content Analysis in Nursing Research: Concepts, Procedures and Measures to Achieve Trustworthiness." Nurse Education Today 24 (2): 105-112. doi:10.1016/j.nedt.2003.10.001.

Havik, T., E. Bru, and S. K. Ertesvåg. 2014. "Parental Perspectives of the Role of School Factors in School Refusal." Emotional \& Behavioural Difficulties 19 (2): 131-153. doi:10.1080/13632752.2013.816199.

Havik, T., E. Bru, and S. K. Ertesvåg. 2015a. "Assessing Reasons for School Non-attendance." Scandinavian Journal of Educational Research 59 (3): 316-336. doi:10.1080/00313831.2014.904424.

Havik, T., E. Bru, and S. K. Ertesvåg. 2015b. "School Factors Associated with School Refusal- and Truancy-related Reasons for School Non-attendance." Social Psychology of Education 18 (2): 221-240. doi:10.1007/s11218-015-9293-y.

Hella, B., and G. A. Bernstein. 2012. "Panic Disorder and School Refusal." Child and Adolescent Psychiatric Clinics of North America 21 (3): 593-606. doi:10.1016/j.chc.2012.05.012.

Heyne, D., N. King, and T. Ollendick. 2004. "School Refusal." In Cognitive Behaviour Therapy for Children and Families, edited by P. Graham, 320-341. Cambridge: Cambridge University Press.

Heyne, D. 2006. "School Refusal." In Practitioner's Guide to Evidence-based Psychotherapy, edited by J. E. Fisher and W. T. O'Donohue, 600-619. New York, NY US: Springer Science + Business Media.

Heyne, D., and F. Sauter. 2013. "School Refusal." In The Wiley-Blackwell Handbook of the Treatment of Childhood and Adolescent Anxiety, edited by C. Essau and T. H. Ollendick, 471-517. Chichester: John Wiley \& Sons Limited.

Heyne, D., F. M. Sauter, and B. R. Maynard. 2015. "Moderators and Mediators of Treatments for Youth with School Refusal or Truancy." In Moderators and Mediators of Youth Treatment Outcomes, edited by M. Maric, P. J. M. Prins, and T. H. Ollendick, 230-266. Oxford University Press. doi:10.1093/med:psych/9780199360345.003.0010.

Heyne, D., C. Gentle-Genitty, M. Gren Landell, G. Melvin, B. Chu, M. Gallé-Tessonneau, ... C. A. Kearney. 2019a. "Improving School Attendance by Enhancing Communication among Stakeholders: Establishment of the International Network for School Attendance (INSA)." European Child and Adolescent Psychiatry. doi:10.1007/s00787-019-01380-y.

Heyne, D., F. M. Sauter, T. H. Ollendick, B. M. van Widenfelt, and P. M. Westenberg. 2014. "Developmentally Sensitive Cognitive Behavioral Therapy for Adolescent School Refusal: Rationale and Case Illustration." Clinical Child and Family Psychology Review 17: 191-215. doi:10.1007/s10567-013-0160-0.

Heyne, D., M. Gren Landell, G. Melvin, and C. Gentle-Genitty. 2019b. "Differentiation between School Attendance Problems: Why and How?" Cognitive and Behavioral Practice 26: 8-34. doi:10.1016/j.cbpra.2018.03.006.

Hochadel, J., J. Frölich, A. Wiater, G. Lehmkuhl, and L. Fricke-Oerkermann. 2014. "Prevalence of Sleep Problems and Relationship between Sleep Problems and School Refusal Behavior in School-Aged Children in Children's and Parents' Ratings." Psychopathology 47 (2): 119-126. doi:10.1159/000345403.

Ingul, J., T. Havik, and D. Heyne. 2019. "Emerging School Refusal: A School-based Framework for Identifying Early Signs and Risk Factors." Cognitive and Behavioral Practice 26: 46-62. doi:10.1016/j.cbpra.2018.03.005.

Ingul, J. M., and H. M. Nordahl. 2013. "Anxiety as a Risk Factor for School Absenteeism: What Differentiates Anxious School Attenders from Non-attenders?" Annals of General Psychiatry 12 (1): 25. doi:10.1186/1744-859X-12-25. 
Kearney, C. A. 2008. "School Absenteeism and School Refusal Behavior in Youth: A Contemporary Review." Clinical Psychology Review 28 (3): 451-471. doi:10.1016/j.cpr.2007.07.012.

Kearney, C. A., and A. Bensaheb. 2006. "School Absenteeism and School Refusal Behavior: A Review and Suggestions for School-Based Health Professionals." Journal of School Health 76 (1): 3-7. doi:10.1111/josh.2006.76.issue-1.

Kearney, C. A., and W. K. Silverman. 1990. "A Preliminary Analysis of A Functional Model of Assessment and Treatment for School Refusal Behavior." Behavior Modification 14 (3): 340-366. doi:10.1177/01454455900143007.

Knollmann, M., V. Reer, S. Kiessling, and J. Hebebrand. 2013. "[The Differential Classification of School Avoidance- a Cluster-analytic Investigation]." Zeitschrift fur Kinder- und Jugendpsychiatrie und Psychotherapie 41 (5): $335-345$. doi:10.1024/1422-4917//a000248.

Landis, J. R., and G. G. Koch. 1977. "The Measurement of Observer Agreement for Categorical Data." Biometrics 33 (1): 159-174. doi:10.2307/2529310.

Last, C. G., and C. C. Strauss. 1990. "School Refusal in Anxiety-disordered Children and Adolescents." Journal of the American Academy of Child and Adolescent Psychiatry 29 (1): 31-35. doi:10.1097/00004583-199001000-00006.

Le Heuzey, M.-F., and M.-C. Mouren. 2010. Phobie scolaire. Comment aider les enfants et les adolescents en mal d'école?. 2ème ed. J.Lyon.

Marcelli, D., and A. Braconnier. 2013. Adolescence Et Psychopathologie 8e. 8e ed. Elsevier Masson.

McAnanly, E. 1986. "School Phobia: The Importance of Prompt Intervention." The Journal of School Health 56 (10): 433-436. doi:10.1111/josh.1986.56.issue-10.

McCune, N., and J. Hynes. 2005. "Ten Year Follow-up of Children with School Refusal." Irish Journal of Psychological Medicine 22 (2): 56-58. doi:10.1017/S0790966700008946.

Mcshane, G., G. Walter, and J. M. Rey. 2001. "Characteristics of Adolescents with School Refusal." Australian and New Zealand Journal of Psychiatry 35 (6): 822-826. doi:10.1046/j.1440-1614.2001.00955.x.

McShane, G., G. Walter, and J. M. Rey. 2004. "Functional Outcome of Adolescents with "School Refusal"." Clinical Child Psychology and Psychiatry 9 (1): 53-60. doi:10.1177/1359104504039172.

Nishida, A., S. Sugiyama, S. Aoki, and S. Kuroda. 2004. "Characteristics and Outcomes of School Refusal in Hiroshima, Japan: Proposals for Network Therapy." Acta Medica Okayama 58: 241-249. doi:10.18926/AMO/32103.

Okuyama, M., M. Okada, M. Kuribayashi, and S. Kaneko. 1999. "Factors Responsible for the Prolongation of School Refusal." Psychiatry \& Clinical Neurosciences 53 (4): 461-469. doi:10.1046/j.1440-1819.1999.00585.x.

Park, M.-H., H.-W. Yim, S. Park, C. Lee, C.-U. Lee, S. C. Hong, ... J. Choi. 2015. "School Refusal Behavior in South Korean First Graders: A Prospective Observational Community-based Study." Psychiatry Research 227 (2-3): 160-165. doi:10.1016/ j.psychres.2015.04.011.

Place, M., J. Hulsmeier, S. Davis, and E. Taylor. 2002. "The Coping Mechanisms of Children with School Refusal." Journal of Research in Special Educational Needs 2 (2): 1-10. doi:10.1111/jrse.2002.2.issue-2.

Reid, K. 2013. Managing School Attendance: Successful Intervention Strategies for Reducing Truancy. Routledge.

Richards, H. J., and J. A. Hadwin. 2011. "An Exploration of the Relationship between Trait Anxiety and School Attendance in Young People." School Mental Health 3 (4): 236-244. doi:10.1007/s12310-011-9054-9.

Rubenstein, J. S., and E. M. Hastings. 1980. "School Refusal in Adolescence: Understanding the Symptom." Adolescence 15 (60): 775-782.

Salemi, A. T., and K. M. Brown. 2003. "School Phobia: Implications for School Health Educators." American Journal of Health Education 34 (4): 199-205. doi:10.1080/19325037.2003.10761864.

\section{Appendix}

\section{Interview Schedule for Adolescents Not Displaying School Refusal}

I propose that we discuss absenteeism and anxiety at school. The purpose of the questions l'd like to ask is to understand how school phobia/school refusal manifests itself and how it can be identified.

Description of your own experience of anxiety and stress at school:

(1) Are you sometimes absent from school ?

(2) Have you ever had trouble going to school?

(3) How did you react? What did you do ?

(4) Why was it more difficult than usual?

(5) What happened next ?

Manifestations of school refusal:

(6) What do you know about school refusal or school phobia?

(7) Could you tell me more about the teenagers you know who displayed school refusal? 
(8) What do you think are the behaviours at school of adolescents displaying school refusal ?

(9) When did you start asking yourself questions about what was going on for this teenager? What surprised you? What alerted you?

(10) What have you learned about school refusal from teenagers who have displayed school refusal, or from others in your class?

(11) What have adolescents displaying SR told you about their feelings ?

(12) How would you describe a student who suffers from school refusal, to someone who knows nothing about it?

(13) In your opinion, when a student displaying SR feels bad (that is, when they seem to feel uncomfortable at school), what do they do to avoid anxiety ? What do you think their tips would be for coping with their anxiety?

(14) What do you think are the behaviours in the classroom of adolescents displaying SR?

(15) Their attitude/behaviour with your classmates?

(16) During the lunch? The recess?

(17) With the teachers?

(18) With others adults at school?

(19) In your opinion, did he/she take time away from school at particular times? (For example, Monday mornings, test days, sports classes ...? ?)

(20) Was he/she late to school?

(21) Who do you think was the first person to worry, to notice something, to ask questions?

(22) In the school, did a teacher or anyone else notice the school refusal? Did the student asks someone for help?

(23) In your opinion, can we identify (in the school) some clue that could lead us to believe that a student display school refusal?

(24) According to you, how can we detect these students earlier?

(25) In your opinion, what are the first signs of SR that school professionals could identify?

\section{Interview Schedules for Adolescents Displaying SR}

I propose that we discuss absenteeism and anxiety at school. The purpose of the questions l'd like to ask is to understand how school phobia/school refusal manifests itself and how it can be identified.

(1) Who do you live with at home?

(2) How are things going at home?

(3) What do you do in your free time (weekend, hobbies ...)?

(4) According to you, what were the first manifestations/signs of your SR ?

(5) When did you start wondering about what was happening to you ?

(6) What were the very first signs of school refusal at school?

(7) What has changed for you since you started having difficulty going to school ?

(8) What has changed for you at home and between you and your parents since you started having difficulty going to school?

(9) How does it work in the morning before going to school? Could you describe a typical morning before school ?

(10) Since you have had SR, what is different about the evening before school ?

(11) Since you have had SR, what has change with regard to your hobbies?

(12) Since you have had SR, what has changed with regard to your health ?

(13) Since you have had SR, what is different about doing your homework?

(14) How did you and your family explain your absence from school? What reasons did you give to people at school?

(15) How would you describe a student displaying SR, to someone who knows nothing about SR?

(16) What do you think are the behaviours at school of adolescents displaying school refusal ?

(17) How were you in class? What was different from usual? What were your behaviours, your feelings ?

(18) With your classmates, what was different from usual?

(19) During the lunch? The school break?

(20) With the teachers?

(21) With the other adults at school? What was different from usual?

(22) When you feel bad at school, what do you do ? What are your tips to cope with your anxiety?

(23) In your opinion, is there some particular moment where it's more difficult to go to school ? Some typical moment you are more likely to be absent? For example, Monday morning, test days, sports classes ... ? Or were you late?

(24) Had you identified a time of year when this type of absence is more likely to occur?

(25) Who do you think was the first person to worry about you, to notice something was wrong, to ask you questions?

(26) In school, did a teacher or anyone else notice you feel bad?

(27) Did you ask someone for help or did you talk about it?

(28) According to you, what are the first signs of SR that school professionnals could identify ?

(29) In your opinion, how long did it take from the onset of the SR to the first medical consultation? 
(30) According to you, how can we detect these students earlier?

\section{Interview Schedule for Care Professionals}

I propose that we discuss about school refusal in adolescence. The purpose of the questions I'd like to ask is to understand how school refusal manifests itself and how it can be identified.

(1) In your opinion, how does school refusal manifest itself at the beginning, when it first starts?

(2) What do you think are the behaviours at school of adolescents displaying school refusal ?

(3) How would you describe these adolescents at home?

(4) How would you describe these adolescents when they are not at school and not at home?

(5) According to you, what are the firsts manifestations/signs of SR ?

(6) In your opinion, what are the manifestations of SR in the school setting?

(7) According to you, what are the differences between the behaviours of youth displaying SR and the behaviours of youth truanting from school?

(8) In your opinion, what are the behavioural manifestations of avoidance?

(9) In your opinion, how these children behave in the classroom?

(10) Their attitude/behaviour with their peers?

(11) During the lunch ? The school break?

(12) With the teachers?

(13) With others adults at school?

(14) When they feel bad (when they seem to feel uncomfortable) at school, what do they do ? What are their tips to cope with their anxiety?

(15) In your opinion, did he/she take time away from school at particular times? (For example, Monday mornings, test days, sports classes ... ?)

(16) Was he/she late to school ?

(17) Had you identified a time of year when this type of absence is more likely to occur?

(18) In your opinion, what are the first signs school professionals may notice in a student who finds it difficult to attend school?

(19) According to you, what is the first signs the school staff see that lead them to be concerned about a young person?

(20) In your opinion, who is the most appropriate person at school to identify students displaying SR?

(21) In your opinion, how do families explain to school staff the absence of their child? What are the reasons given?

(22) How long do you think it takes from the onset of the SR to the first medical consultation?

(23) According to you, how can we detect these students earlier?

\section{Interview Schedules for Middle School Professionals}

I propose that we discuss about school refusal in adolescence. The purpose of the questions I'd like to ask is to understand how school refusal manifests itself and how it can be identified.

(1) How would you describe the students in your school in general?

(2) In what type of situations have you been confronted with the problem of absenteeism?

(3) When a student is absent, what happens? Do you have a procedure? If so, what is it?

(4) When a teenager is missing, at what point do you start talking about school attendance problem?

(5) What are the reasons for absenteeism that are frequently found? Are absences often justified?

(6) Are you in touch with these families?

(7) Have you ever heard of school refusal or school phobia?

(8) In your experience, have you ever met students displaying SR?

(9) How would you describe a student displaying SR to someone who knows nothing about SR ?

(10) What do you think are the behaviours at school of adolescents displaying school refusal ?

(11) According to you, what are the differences between the behaviours of youth displaying SR and the behaviours of youth truanting from school?

(12) In your opinion, what are the manifestations of SR in the school setting?

(13) In your opinion, how these children behave in the classroom?

(14) Their attitude/behaviour with their peers?

(15) During the lunch? The school break?

(16) With the teachers?

(17) With others adults at school?

(18) According to you, what are the first manifestations/signs of SR? 
(19) In your opinion, did he/she stay away from school at particular times (For example, Monday mornings, test days, sports classes ...)?

(20) In your opinion, was he/she late to school ?

(21) Had you identified a time of year when this type of absence is more likely to occur?

(22) In cases of school refusal, how does the family explain the young persons' absence from school? What reasons do they give to you or others at school?

(23) In your opinion, who is the most appropriate person within the school to identify students displaying SR?

(24) According to you, how can we detect these students earlier? 